\title{
AVALIAÇÃO AMBIENTAL DOS RESÍDUOS PRODUZIDOS PELAS EMPRESAS METALÚRGICAS LOCALIZADAS NO PERÍMETRO URBANO DA CIDADE DE IJUÍ
}

Maria de Lourdes Bellinaso, Adriana Aparecida Soares, Francesca Werner Ferreira, Eva Teresinha Boff e Clarinês Hames

Departamento de Biologia e Química

UNIJUí - ljuí, RS

\section{RESUMO}

Este trabalho teve como objetivo, avaliar os tipos $e$ as quantidades de resíduos produzidos pelas empresas metalúrgicas da cidade de ljuí. A relação das 78 empresas metalúrgicas foi extraída do Cadastro dos Tributos Municipais/96, fornecido pela Secretaria de Indústria, Comércio e Turismo de ljuí, no entanto apenas 40 empresas foram avaliadas. As restantes foram fechadas (14) ou não foram localizadas (24). A avaliação foi realizada através de questionário aplicado in loco, no período de junho/96 a fevereiro/97. Os dados numéricos, referentes as quantidades de resíduos representam, um valor médio mensal estimado pelas empresas. Os resíduos produzidos em maior quantidade são: metais, areia de fundição, papel de escritório e resíduos de refeitório. A quantidade total de resíduos produzidos é de $48.809 \mathrm{Kg} / \mathrm{mês}$, sendo que $14.711 \mathrm{Kg} / \mathrm{mês}$ é reciclato. Os resíduos encaminhados para 
reciclagem eram vendidos, reciclados pela empresa, ou ainda, doados. Os resíduos não reciclados $(34.098 \mathrm{Kg} / \mathrm{mês})$ eram depositados em terrenos baldios, queimados ou enviados ao depósito municipal. A areia de fundição, resíduo produzido em maior quantidade, não está sendo mais produzida; neste caso a quantidade total de resíduos produzidos passa para 18.809 $\mathrm{Kg} / \mathrm{mês}$, com um percentual de reciclagem de $78 \%$.

\section{SUMMARY}

The present work has as its main objective the assessment of the kind and quantity of waste produced by the metallurgic industries in the city of ljuí. The roll of the 78 metallurgic plants was drawn from the ROLL OF CONTRIBUTORS/96 provided by the BUREAU OF COMERCE, INDUSTRY AND TOURISM OF IJUII. In spite of this number, only 40 firms were assessed because the others were closed (14) or not found (24). The assessment was made through a questionaire applied $\underline{\mathbb{I N} \text { LOCO }}$ in a period comprised between June/96 to February/97. The numeric data about the amount of waste is a monthly average value estimated by the firms themselves. The waste produced in higher amounts are: metals, fusing sand, office paper and dining hall scraps. The total amount of waste produced makes 48.809 $\mathrm{Kg} /$ month, being $14.711 \mathrm{Kg} / \mathrm{month}$ are reciclated. The waste not recycled makes $34.098 \mathrm{Kg} /$ month and is sent to junk yards, burnt or thrown in the municipal waste deposit lot. The fusing sand, wich is the waste produced in major amounts of size, isn't produced anymore. In this case the total amount of waste produced goes to $18.809 \mathrm{Kg} /$ month, with a recycling percentage of $78 \%$.

Palavras chaves: Resíduos Industriais, Diagnóstico Ambiental. 


\section{1 - INTRODUÇÃO}

Os processos artesanais e industriais de transformação de metais fazem parte da história do desenvolvimento econômico do município de ljuí (RS). Na década de trinta haviam 50 estabelecimentos no município que trabalhavam com ferraria e funilaria; localizavam-se na sede e principalmente no interior do município. Os trabalhos sobre metais no meio rural, denominados de "artesanato rural", eram realizados pelos próprios agricultores e atendiam as demandas agrícolas da região (WEBER, 1987).

Os produtos metalúrgicos fabricados desde o início da colonização em ljuí - moinhos, atafonas, engenhos de serras, prensas para cana-de-açúcar, fumo, banha, ferragens em geral, latarias, utensílios domésticos, implementos e máquinas agrícolas, estruturas metálicas para construção civil -, mostram os caminhos tomados no desenvolvimento deste município (WEBER, 1987).

Atualmente o município de ljuí conta com 382 empresas das quais 82 são metalúrgicas, sendo que 78 estão localizadas no perímetro urbano do município (Secretaria da Indústria, Comércio e Turismo de ljuí, 1996). As empresas metalúrgicas representam um percentual de $21 \%$ do total de empresas do município.

Os processos metalúrgicos utilizam como matéria prima principalmente alumínio, ferro, manganês, níquel, cromo, molibdênio, cobre, estanho, cádmio, chumbo. Alguns destes metais, e outros tipos de resíduos produzidos no processo metalúrgico, como areia de fundição, são tóxicos em pequenas quantidades, portanto, o gerenciamento inadequado dos resíduos produzidos pelas metalúrgicas podem contaminar o solo e as águas $e$ consequentemente os seres vivos terrestres e aquáticos.

Este trabalho teve o objetivo de conhecer, pela primeira vez em ljuí, após um século de trabalhos de manipulação sobre o metal, o gerenciamento atual dos resíduos produzidos pelas empresas metalúrgicas localizadas no perímetro urbano desta cidade, com a finalidade de incentivar 
e subsidiar uma política de gerenciamento de resíduos industriais para o município.

\section{2 - MATERIAL E MÉTODOS}

A relação das empresas metalúrgicas foi extraída do cadastro/96 dos Tributos Municipais, fornecido pela Secretaria da Indústria, Comércio e Turismo de ljuí (Prefeitura Municipal de ljuí, 1996).

Neste cadastro as empresas são classificadas, segundo a sua renda empresarial, em micro empresas (renda menor que 12.000 UFIRs/ano) e em empresa normal (renda maior que 12.000 UFIRs/ano) (Prefeitura Municipal de ljuí, 1985).

A avaliação sobre os resíduos metalúrgicos produzidos em ljuí foi realizada através de um questionário, aplicado in loco, que investigou a matéria prima utilizada, o tipo, a quantidade e o tratamento dos resíduos sólidos, líquidos e gasosos produzidos pelas empresas metalúrgicas localizadas no perímetro urbano de ljuí. Neste questionário, também, foi investigado algumas concepções ambientais do responsável pelas informações sobre os resíduos produzidos pelas empresas, como: preocupações sobre o impacto ambiental, elementos do ambiente impactado, opinião sobre a situação atual do lixo urbano em ljuí e suas disposições de colaborarem com a coleta seletiva do lixo.

Os dados numéricos, referentes as quantidades de resíduos produzidos pelas empresas, representam um valor médio mensal estimado pela empresa.

A investigação ocorreu no período de junho/96 a fevereiro/97. O número de empresas metalúrgicas localizadas no perímetro urbano de ljuí é 78 , sendo que o questionário foi aplicado em 40 empresas (27 normais e 13 micro), 14 foram fechadas e 24 não foram localizadas no endereço indicado no cadastro. 


\section{3 - RESULTADOS E DISCUSSÃO}

As principais matérias primas utilizadas nas 40 empresas metalúrgicas investigadas são: aço, ferro, alumínio, chapa de flandres, bronze e estanho. Os produtos fabricados em maior escala são: máquinas e implementos agrícolas, estruturas metálicas para construção (aberturas, grades, calhas, tesouras para coberturas, caixa d'água), utensílios domésticos (panelas, torradeiras, formas, baldes, tábuas de lavar roupa, canos de fogão), telas, escadas e antenas parabólicas.

As empresas diagnosticadas não relataram a produção de resíduos líquidos, e não mencionaram uma estimativa sobre as quantidades de resíduos gasosos produzidos, como por exemplo os gases liberados na fundição e na queima de combustíveis.

Os resíduos sólidos são provavelmente os produzidos em maior quantidade pelas empresas metalúrgicas de ljuí. Os tipos de resíduos sólidos produzidos no processo metalúrgico são: metais, areia de fundição, papel de escritório, resíduos de refeitório e outros (cera de abelha, maravalha, serragem, estopa, lixa, cinza de alumínio, rebites e cinzas provenientes da combustão).

A quantidade total de resíduos sólidos produzidos nas 40 empresas diagnosticadas é estimada em $48.809 \mathrm{Kg} / \mathrm{mês}$, sendo que 14.711 $\mathrm{Kg} / \mathrm{mês}(30 \%$ do total de resíduos) é reciclado e $34.098 \mathrm{Kg} / \mathrm{mês}$ ( $70 \%$ do total de resíduos) não é reciclado, Quadro - 1.

A soma dos resíduos sólidos, areia de fundição (30.000 $\mathrm{Kg} /$ mês) e metais $(17.950 \mathrm{Kg} / \mathrm{mês})$, representa um percentual de $98 \%$ do total de resíduos produzidos, Quadro - 1.

Os resíduos metálicos são reciclados em 80\%, Quadro - 1. Este alto percentual tem relação com o fluxo acessivel de reciclagem existente na região de ljuí, que traz um retorno financeiro à empresa. A reciclagem dos resíduos metálicos (aparas de chapa, ferro, bronze, inox, etc.) é realizada através da venda para empresas maiores que fundem estes resíduos para sua reutilização. Os resíduos metálicos não reciclados são 
aqueles de menor tamanho (bojo, limalhas de ferro) que muitas vezes encontram-se em uma mistura que dificulta a sua reciclagem, Quadro - 2.

O resíduo sólido produzido em maior quantidade pelas empresas foi a areia de fundição, $30.000 \mathrm{Kg} / \mathrm{mês}$ (61,5\%), Quadro 1. As areias de fundição, podem ser classificadas como resíduos de Classe I ( perigoso ) ou de Classe II ( não inerte), devido a presença de substâncias fenólicas. Estes resíduos de Classe I e II são potencialmente tóxicos e quando dispostos de maneira inadequada podem contaminar as águas superficiais e subterrâneas através de processos de lixiviação e percolação. Portanto, as areias de fundição necessitam ser depositadas em aterros sanitários de solo impermeável, que impeçam o arraste destas substâncias tóxicas (LIMA, 1991; ABNT, 1986). Esta areia de fundição tem sido depositada em terrenos baldios dentro e fora do perímetro urbano, Quadro-2.

O tipo de resíduo que apresenta maior percentual de reciclagem (95\%) são os resíduos de refeitório, que após serem enviados para a zona rural, são utilizados para alimentação animal e para a fertilização do solo. Outros resíduos como maravalha, serragem, cera de abelha também são encaminhados para reciclagem no meio rural, Quadros - 1 e 2.

Dos papéis produzidos pelos escritórios das empresas, apenas $27 \%$ são reciclados. Esta percentagem é baixa, uma vez que a cidade ljuí tem um bom fluxo de encaminhamentos para reciclagem (catadores de rua, mercado de compra, doações para entidades sociais economicamente carentes).

Muitos dos resíduos que não são reciclados estão sendo colocados em terrenos baldios dentro e fora do perímetro urbano, ocasionando proliferação de vetores de doenças e contaminando solo, água e ar e , também, muitas vezes são queimados no local de depósito. Estas atitudes, depósito inadequado e queima, têm causado muitas reclamações da sociedade junto a Promotoria Pública, uma vez que elas têm aflorado processos patológicos na população (Ministério Público do Rio Grande do Sul, 1993/1996). Entre os períodos de 93-96 foram realizadas cinco perícias 
sobre questões de depósito de lixo dentro do perímetro urbano de ljuí.

Alguns resíduos não reciclados, são queimados pela própria empresa. A queima de qualquer resíduo é proibida pela Legislação Estadual (Rio Grande do Sul, 1993), uma vez que produz substâncias tóxicas conhecidas e outras que fogem ao conhecimento da ciência.

Novos valores numéricos se alinham se a areia de fundição não é contabilizada na estimativa mensal na produção de resíduos, Figura - 1.

$\mathrm{Na}$ figura - 1 podemos observar uma mudança significativa na quantidade e no percentual de reciclagem dos resíduos produzidos pelas empresas metalúrgicas de ljuí, não contabilizando a areia de fundição. A quantidade total de resíduos produzidos, contabilizando a areia de fundição é $48.809 \mathrm{Kg} / \mathrm{mês}$ com um percentual total de reciclagem de $30 \%$; a quantidade total de resíduos, não contabilizando as areias de fundição, é $18.809 \mathrm{Kg} / \mathrm{mês}$ com um percentual de reciclagem de $78 \%$.

Foi detectado em uma empresa uma tonelada de cianeto proveniente dos processos metalúrgicos de galvanização, já desativados. Este produto encontra-se depositado na própria empresa.

A quantidade total de energia elétrica utilizada pelas indústrias diagnosticadas é de $114.399 \mathrm{KW} / \mathrm{mês}$. Algumas empresas utilizam, além da energia elétrica, a energia proveniente da combustão química (gás, óleo, madeira).

Alguns dos entrevistados (em número de 27 ), geralmente o dono da empresa ou um funcionário inserido na manipulação dos resíduos, foram também questionados sobre algumas de suas concepções ambientais. Os resultados obtidos foram:

- $80 \%$ do entrevistados expressaram preocupações com as questões referentes ao impacto ambiental;

- os elementos do ambiente apontados como impactados foram: rios, mananciais aquáticos ( 7 entrevistados ), reflorestamento, flora 
(7 entrevistados), fauna (4 entrevistados), natureza ( 7 entrevistados ), solo ( 1 entrevistado), meio ambiente (1 entrevistado);

-.67\% não aprovam a situação atual do lixo urbano de ljuí e $33 \%$ desconhecem tal situação;

- todos os entrevistados estão dispostos a colaborar com a coleta seletiva do lixo de ljuí.

\section{4 - CONCLUSÃO}

As considerações finais sobre este trabalho têm como base os dados médios mensais estimados pelas 40 empresas investigadas, entre junho de 1996 e fevereiro de 1997.

- O cadastro fornecido pela Secretaria de Indústria e Comércio de ljuí/96 está desatualizado, portanto, é necessário realizar um recenseamento das indústrias de ljuí no qual conste os seus processos industriais, bem como os resíduos produzidos. Este recenseamento deve servir como um referencial de controle e orientação para um gerenciamento adequado dos resíduos metalúrgicos, conforme normas da Fundação Estadual de Proteção ao Meio Ambiente (FEPAM).

- A quantidade total estimada de resíduos produzidos pelas empresas no período investigado foi de $48.809 \mathrm{Kg} / \mathrm{mês}$, com um percentual de reciclagem de $30 \%$. Com a desativação do processo de fundição da empresa produtora dos resíduos de areia de fundição, a quantidade total passa a ser $18.809 \mathrm{Kg} / \mathrm{mês}$, com um percentual de reciclagem de $78 \%$.

- A areia de fundição que é considerada resíduo de classe I ( perigoso ) ou II ( não inertes ) foi depositada em terrenos baldios, banhados e próximos a mananciais aquáticos, dentro e fora do perímetro urbano, por aproximadamente quatro décadas ( aproximadamente $30 \mathrm{~T} / \mathrm{mês}$ nos últimos anos). Este gerenciamento desvinculado da preservação ambiental podem estar contaminando as águas superficiais e subterrâneas. 
- Alguns resíduos metálicos e papéis tem potencialidade de reciclagem, portanto, deve-se fazer um trabalho de conscientização para este fim.

- Muitos dos resíduos que não são reciclados estão sendo colocados em terrenos baldios ou queimados. As empresas devem ser orientadas para encaminhar estes resíduos para o depósito municipal de lixo.

- A quantidade de resíduos gasosos não é estimada pelas empresas e não foi relatada a produção de resíduos líquidos pelas metalúrgicas situadas no perímetro urbano de ljuí.

- A evolução dos trabalhos com metais faz parte da história do desenvolvimento econômico do município de ljuí. Sem dúvida, teve uma contribuição marcante no desenvolvimento agrícola de toda região. 0 processo industrial não foi sempre desvinculado das preocupações ambientais. Iniciativas foram tomadas no sentido de desenvolver implementos e máquinas agrícolas que objetivaram um manejo conservacionista do solo (REICHARDT \& DHEIN, 1990). Após um século de trabalho de transformação de metais em ljuí, faz-se necessário analisar e refletir sobre os resíduos produzidos por este processo industrial, encaminhando-os sempre que possivel a reciclagem. Este trabalho não tem o intuito de reprimir as iniciativas empresariais, mas de inserir a reciclagem dentro do projeto econômico administrativo da empresa, uma vez que este projeto deve contabilizar sempre a recuperação e a preservação ambiental. 


\section{BIBLIOGRAFIA:}

ASSOCIAÇÃO BRASILEIRA DE NORMAS TÉCNICAS. Resíduos Sólidos, NBR 10004. Rio de Janeiro: ABNT, 1986. 63p.

FUNDAÇÃO ESTADUAL DE PROTEÇÃO AMBIENTAL. Licença de Operação LO N²607/96-DL. Ijuí : FEPAM/IMASA, 1996.

IJUÍ. Secretaria de Indústria, Comércio e Turismo de ljuí. Cadastro de Tributos Municipais. Ijuí, 1996.

IJUÍ. Prefeitura Municipal. LEI MUNICIPAL № 2.085/85, de 7 de Junho de 1985. ljuí, 1985.

IJUÍ. Ministério Público Do Rio Grande Do Sul. Promotoria de Justiça. Procedimentos Administrativos. Ijuí, 1993/1996.

LIMA, L. M. Q. Tratamento do lixo. São Paulo : Hemus, 1991.

RIO GRANDE DO SUL. Lei Estadual № 9.921, de 27 de Julho de 1993. Diário Oficial, Porto Alegre, 28 de Julho de 1993. N. 142, p. 1-2.

REICHARDT, F. L, DHEIN, R. A.. Um Histórico da "Agropecuária Conservacionista do Solo" em Ijuí - RS. Ijuí : Ed. UNIJUÍ, 1990. 73 p. (Coleção Centenário de ljuí; 8).

WEBER, R.. Os inícios de industrialização em ljuí. ljuí : Ed. UNIJUÍ, 1987. 190 p. (Coleção Centenário de ljuí; 1). 
Tabela1 - Tipos e quantidades mensais de resíduos produzidos pelas Empresas Metalúrgicas de ljuí. Valores estimados pelas empresas.

\begin{tabular}{|l|c|c|c|}
\hline \multicolumn{1}{|c|}{$\begin{array}{c}\text { Tipos de Resíduos } \\
\text { Sólidos }\end{array}$} & $\begin{array}{c}\text { Quantidades } \\
\text { (Kg/mês) }\end{array}$ & Reciclado (kg/mês) & Não Reciclado (kg/mês) \\
\hline Metal & 17.950 & $14.360(80 \%)$ & $3.590(20 \%)$ \\
\hline Areia de Fundição & 30.000 & $0(0 \%)$ & $30.000(100 \%)$ \\
\hline Papel de Escritório & 263 & $71(27 \%)$ & $192(73 \%)$ \\
\hline Refeitório & 126 & $120(95 \%)$ & $6(5 \%)$ \\
\hline Outros & 470 & $160(34 \%)$ & $310(66 \%)$ \\
\hline TOTAL & $\mathbf{4 8 . 8 0 9}$ & $\mathbf{1 4 . 7 1 1}$ & $\mathbf{3 4 . 0 9 8}$ \\
\hline
\end{tabular}


Tabela 2 - Destino final dos resíduos sólidos reciclados e não reciclados produzidos pelas empresas metalúrgicas de ljuí.

\begin{tabular}{|c|c|c|}
\hline $\begin{array}{c}\text { Tipos de Resíduos } \\
\text { Sólidos }\end{array}$ & $\begin{array}{c}\text { Destino dos Resíduos Encaminhados } \\
\text { para Reciclagem }\end{array}$ & $\begin{array}{c}\text { Destino dos Resíduos } \\
\text { Não Encaminhados para Reciclagem }\end{array}$ \\
\hline $\begin{array}{c}\text { Metais } \\
\text { (aparas de chapas, } \\
\text { ferro, bronze, inox) }\end{array}$ & $\begin{array}{l}\text { Vendido, Reciclado na Empresa, } \\
\text { Doado }\end{array}$ & $\begin{array}{l}\text { Depósito Municipal de lixo, Terreno } \\
\text { baldio dentro e fora do Perímetro Urbano } \\
\text { (latas, bojo, limalha de ferro). }\end{array}$ \\
\hline Papel de Escritório & Vendido, Doado & Queimado, Depósito Municipal de Lixo. \\
\hline \begin{tabular}{|c|} 
Refeitório \\
(restos de alimentos, \\
lata, caixas de \\
papelão, madeira, \\
sacos plásticos) \\
\end{tabular} & Recolhido p/ Propriedades Rurais. & $\begin{array}{l}\text { Depósito Municipal de Lixo (restos de } \\
\text { alimentos, latas, caixas de papelão, } \\
\text { madeira, sacos plásticos). }\end{array}$ \\
\hline $\begin{array}{c}\text { Outros } \\
\text { (cera de abelha, } \\
\text { maravalha, } \\
\text { serragem, cinzas } \\
\text { proveniente da } \\
\text { combustão) }\end{array}$ & Recolhido p/ Propriedades Rurais & $\begin{array}{l}\text { Depósito Municipal de Lixo, Queimado, } \\
\text { Aterro dentro do Perímetro Urbano } \\
\text { (estopa, lixas, cinzas de alumínio, rebite). }\end{array}$ \\
\hline Areia de Fundição & & $\begin{array}{l}\text { Terreno baldio dentro e fora do Perímetro } \\
\text { urbano, Banhados }\end{array}$ \\
\hline
\end{tabular}




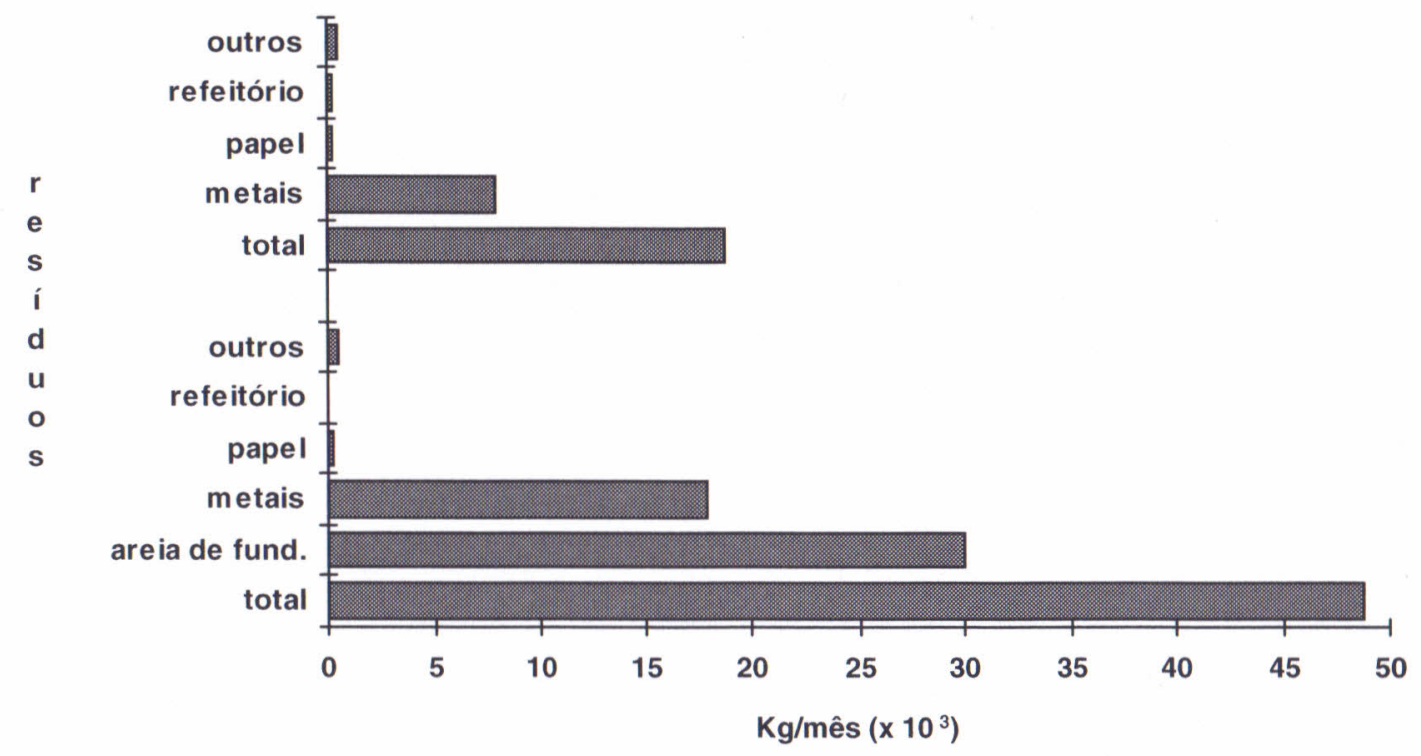

Figura 1 - Quantidade e tipos de resíduos produzidos pelas empresas metalúrgicas de ljuí, contabilizando e não contabilizando a areia de fundição. 


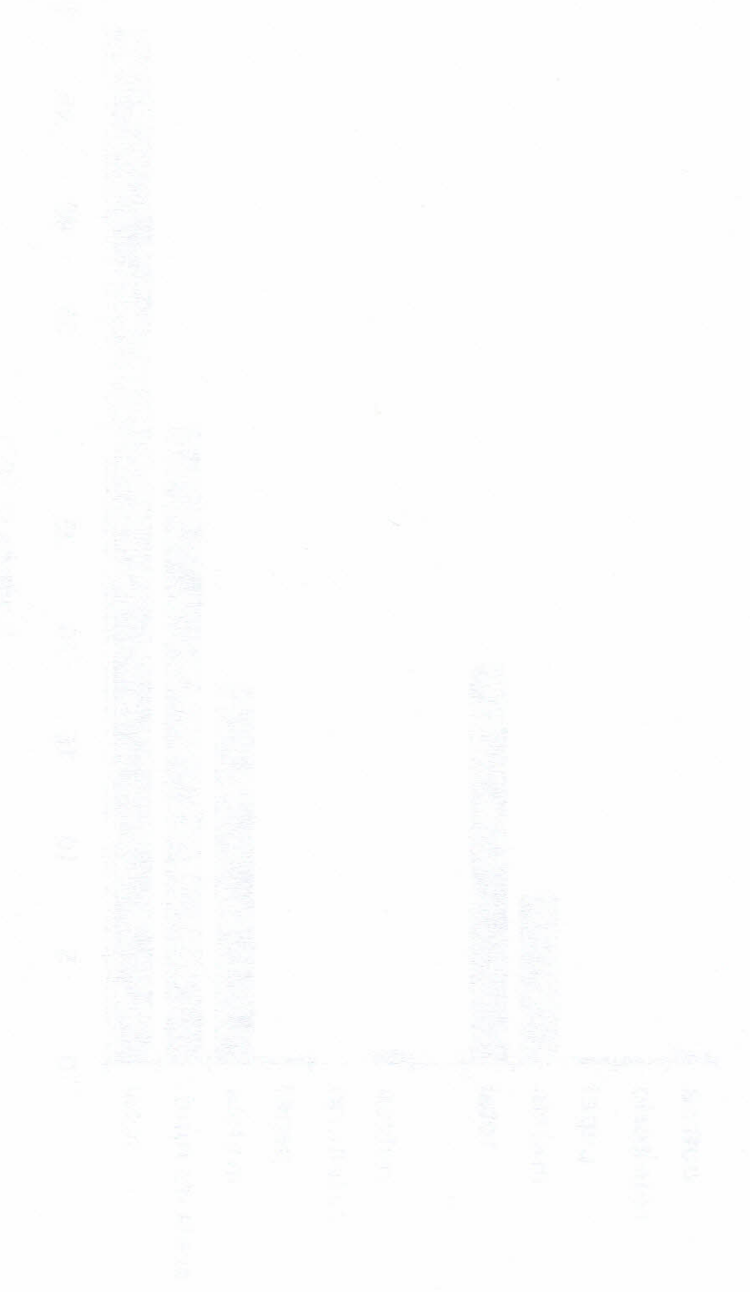

